\title{
The Innovation of Software Engineering Course in The Non-Computer Professional
}

\author{
Shi-yu Huan \\ Department of Automatic, College of Electronics Information Engineering, \\ Inner Mongolia University, \\ Hohhot , Inner Mongolia, China \\ Email:huanli809@gmail.com
}

\begin{abstract}
Starting with the generation of the software engineering, the development of software engineering is discussed in this paper. On this basis, we analyze the shortcomings in traditional software engineering courses. Especially for the characteristics of software engineering course in the non-computer professional, a new method is explored-practice-based teaching methods.
\end{abstract}

Keywords-software engineering, practice-based teaching, software crisis, instance, case methods of teaching.

\section{INTRODUCTION}

From the last century 60's, high-level programming language became popular, the application of computer got a larger expansion and the demand for software also increased sharply. However, due to advances in software technology was relatively slow, the cycle of the software production was relatively longer, readability, reliability and maintainability of the software were far from the needs of society, thus, the development of software technology could not keep up with the growing of the hardware, all these led to the "software crisis." In order to get rid of software crisis in the development of software, the term software engineering first appeared in the 1968 NATO Software Engineering Conference, and was meant to provoke thought regarding the perceived "software crisis" at the time. The software starts from the "individual act" and "stress technique" gradual shifted to "engineering" and "group work" [1]. Although this did not fundamentally solve the problem of software crisis, but the idea of software engineering brings a ray of hope to the staffs in software development.

\section{CHARACTERISTICS OF SOFTWARE ENGINEERING AND PROGRAM REQUIREMENTS}

The IEEE Computer Society's Software Engineering Body of Knowledge defines "software engineering" as the application of a systematic, disciplined, quantifiable approach to the development, operation, and maintenance of software, and the study of these approaches; that is, the application of engineering to software. It is the application of Engineering to software because it integrates significant mathematics, computer science and practices whose origins are in Engineering.

From the appearance of the software engineering concept to the present, it has more than 40 years. The software engineering has gone through four generations. "The first generation" is the traditional software engineering, the structured analysis and design methods were reflected in this generation. "The second generation" is object-oriented software engineering. "The third generation" is the concept of "software process" of software engineering. "The fourth generation "is the component-based development methods of software engineering.

Thus, the pace of development of software engineering is very impressive, and it is also involved in a wide range of subject areas. Now many institutions are still used traditional teaching methods to teach the software development, this must lead what learn is not what use and what learn can not be used. This phenomenon appears in the non-computer science particularly.

Automatic major is computer-related profession. Automation is a comprehensive and younger subject. The main objects of study relate to industry, agriculture, transportation, commerce, defense and many other social fields. It includes automatic control, information processing, data communications, computer applications, science and technology. In the information age, the design of traditional industries, manufacturing and other sectors have been or are intelligent, information technology and automation. These require a large number of advanced automation technology person in science. How to meet the needs of technical application person in the community has also been explored in our teaching and research. Why we offer software engineering course is hope that the students through such a course could understand the various stages of software development process, familiar with the various stages of the necessary methods and tools, develop the ability of abstract analysis and summarize, make up deficiencies in the software design and improve the level of software design

\section{Problems In Traditional Mode of TEACHING}

In the traditional teaching methods, learning and doing are two separate parts. This idea of teaching reflected in software engineering is the software engineering is divided into different stage and different method. The software engineering system and the software engineering practice was artificially divided separately. Teachers teach the concepts, methods, models of software engineering in stages, and even the scope of study and examination are pre-configured. In this teaching process, students can only learn the fragments of knowledge. Although some things have been talked in class, but the students never thought how to use it in practice, therefore, it is difficult for them to use software engineering knowledge to solve specific problems. This will definitely affect the students' understanding and effective application for knowledge. In the traditional 
indoctrination teaching, the teacher stands on the stage, the students sit to listen what the teacher is saying. For a long time, the students are in the state of passive acceptance.For example, when the teacher explains the software process model, the waterfall model, prototyping model, spiral model, rapid application development model and features of the model are listed in the textbooks, and the corresponding diagrams are also given, if the teacher only introduces these frame content to the students in their teaching, students often only have a shallow understanding of the basic concepts, how to apply these models in practice, how to use these models to solve problems and other practical skills which can really help them to improve the knowledge could not be explained by this single way.

\section{THE RECOGNITION AND EXPLORATION OF Practice-Based Teaching Methods}

With the arrival of the new century, the rapid development of the economy and the competition has become increasingly more and more intense. The demand for the quality of talent has also become increasingly higher and higher. Especially in the era of knowledge economy, the economic competition has transformed into the competition for talent. In the competitions, who has high-quality personnel, who are able to remain an invincible position. The level of the quality of talent largely depends on the education system, the quality of education and the teaching methods. Thus, the teaching method reform is imminent and is facing serious challenges. Change the traditional concepts of teaching and improve the untimely teaching methods have become imperative. The case teaching is one of the important ways to improve the overall quality of students, and is also indeed a good way to reform teaching methods.

Software engineering is a very strong practical discipline, but in the mode of traditional teaching, it is difficult for students to truly understand the practical, therefore, it is very difficult for the students to apply the knowledge of software engineering to software development. So, what can we do to make up the shortcomings of traditional teaching model? How can we truly combine theory with practice? After groping in the practical teaching, I consider that practical teaching method for teaching software engineering should be effective. That can greatly improve the students' interest and stimulate the curiosity of students, then help students master the theoretical knowledge and ultimately improve the quality of teaching, so as to develop the creativity and ability to solve practical problems of the students.

Using practical teaching methods in teaching software engineering course is inspired by the case methods of teaching. The case methods of teaching are a method of teaching using the case. It is very popular and effective in the United States. In 1910, the case methods of teaching were first used in the Harvard Business School. The case methods of teaching were introduced into China in the early 1980s, and now it is slowly widely used. The case methods of teaching are based on basic knowledge and analytical techniques of the students. According to the purpose of teaching and teaching requirements, teachers use a typical case to enable students to participate in case studies. Through independent think and cooperation, it will further improve the ability of identification, analysis, and solving a specific problem of the student.

So, how to apply the case methods of teaching to software engineering? I think, the first is to determine the content of students teaching according to their current level of knowledge. Because computer software programs in our teaching programs are not as focused courses, so the theoretical knowledge and practical ability of students in computer software are relatively weak, but the theory and practice of professional of them is strength. In this actual case, firstly, we add the analytical content of automatic control system in teaching and explain the theory of knowledge in software engineering as easier as possible. To begin the actual case, we explain the theoretical knowledge with case analysis and we also introduce the open source software as teaching example, for example Linux. Actual results also show that the cases are more easily impressed in their mind, may stimulate their interests in learning, and the theory of knowledge also has been sublimated.

Secondly, the way in teaching should also be changed from the previous lecture-based teaching methods. During explaining the case, the teacher should increase discussing time in the classroom and guide students to record the detailed case of discussing, and that will help the students change the contents explained in the class into their own knowledge. Meanwhile, after explaining each chapter, the teacher will layout the related actual case to the students and ask the students to gather in small groups, extract learning information, prepare cases for analysis and discussion and write a summary report. The teacher can also organize students to identify problems and propose ideas in the form of reporting in the class, it will enable students to promote each other.

A prominent feature of the knowledge era is that speed of updating knowledge is accelerated. Experts estimate that $90 \%$ of the human application of knowledge which will be used in 2020 has not been created yet. Today's college students who will graduate, the knowledge they have learned is obsolete or nearly obsolete. In teaching, the prominent problem is that the theory is seriously out of practice. If you do not adjust the teaching content as soon as possible, and to update the knowledge structure of teachers, the students we trained will be left out by society. The case teaching will conducive to link theory with practice, and to improve the quality of teaching.

The several years of teaching practice has proved that this teaching method not only enriches the content of the classroom and actives classroom atmosphere, but also greatly enhanced the enthusiasm of students to achieve a very good teaching.

Case teaching will facilitate students' logical thinking ability and problem-solving skills. On how to improve thinking ability, the educator Pujieluofu once said: "Thinking is always started from the problem." Case analysis is a series of questions to the students through case for thinking, students always learn with a problem. Thinking from the problem, after some thought, they will understand which 
they do not know originally, or for new problems, after re-thinking and they will obtain the new knowledge. This approach can help the students to deepen their understanding ability and to improve their logical thinking ability.

Since software engineering develops with the software technology, so, the teachers should be able to grasp the latest developments to guide students to grasp the latest tools. This allows the teacher to maximize the enthusiasm of students and interest in learning in the limited hours, and will provide students more opportunities to practice with their own. The quality of teaching will be more increase.

Through the teaching practice, this more practical teaching method will continue to introduce new ideas in teaching and guide students to continue to think the problem with new point of view. Not like in the traditional teaching, the knowledge obtained is abstract, over-generalization and rigid. The knowledge gained by students will be more practical knowledge. It will be more easily accepted and understood by students. It will be more effective for students to put the knowledge into practice also.

\section{REFERENCES}

[1] Yang Fuqing, Mei Hong: Some Discussion on the Development of Software Technology. Acta Electronica Sinica, 2002, 30 (12A) , pp. 1901-1906.

[2] Zhang xiaoxiang: Encyclopedia of Computer Science and Technology. Tsinghua University Press, Beijing, 1998.

[3] Qin Zheng, He Jian: Software Engineering and Management. Tsinghua University Press, Beijing, 2005.

[4] Jin Zunhe: Introduction to Software Engineering Practice. Tsinghua University Press, Beijing, 2005.

[5] Yang Fuqing: Thinking and Practice of Software Engineering Education. The National University Software Engineering Academic Conf., 2007, pp. 9-15.

[6] Wang Xin, Wang Juan: The Discussion on Case Teaching of Software Engineering. Computer and Information Technology, vol.6, 2006.

[7] Shen Beijun, Gu Chunhua, Yu Huiqun: The thinking and Innovation of Software Engineering Education. Chemical Education, vol.4, 2005. 